\title{
Modelling Tension Strength Behaviour of Structural Lumber Exposed to Elevated Temperatures
}

\author{
PETER W. LAU \\ Forintek Canada Corp. \\ Québec, Canada \\ J. DAVE BARRETT \\ Faculty of Forestry \\ Department of Wood Science \\ University of British Columbia, Canada
}

\begin{abstract}
The design of wood-frame structural systems to withstand exposure to fire depends on knowledge of the fire endurance (time to failure) of the wood members in these systems. In fires, wood looses part of its load-carrying capacity to charring and part to strength degradation. The design must also consider factors such as loads in the system, heat transfer, wood quality and member size. All these variables interact to affect the time to failure. This paper summarizes the results of a Forintek study on the strength behaviour of structural wood members stressed in tension and exposed to elevated temperatures. Approximately 1200 pieces of lodgepole pine Machine-StressRated (MSR) lumber were tested in tension under various temperature and load-rate histories. Results indicate that strength losses are significant. A model developed to predict the time to failure has been applied to predict the mean short-term strength as a function of temperature of exposure and duration of exposure.
\end{abstract}

KEYWORD: wood, lumber, tensile strength, modelling, elevated temperature.

\section{INTRODUCTION}

Modern engineered wood structural systems are usually assembled from light-framing lumber having thickness $38 \mathrm{~mm}$ and width dimensions from 38 and $235 \mathrm{~mm}$. Our knowledge of their structural performance, and particularly their composite behaviour and load-sharing between elements, has been steadily advanced. The design of these systems to perform under normal 
operating conditions has become very efficient. With respect to fire exposure, the design for fire safety has remained relatively unchanged and has not accounted for redundancy lost to improved structural efficiency. Consequently, the ability of modern engineered wood-frame systems to maintain adequate fire endurance has been questioned [1]. While such concerns are legitimate, the issue should be addressed from the viewpoint of reliability. Reliability approach will provide the needed input to performance evaluation and risk-cost assessment of fire-rated structures. Knowledge of the behaviour of wood elements exposed to fire must therefore be advanced to permit calculation of reliability. Information about strength degradation of wood is lacking for the temperature range between $50^{\circ} \mathrm{C}$ and $300^{\circ} \mathrm{C}$.

In wood designs, tension stress is the most dangerous kind of stress to deal with because of wood's brittle nature. Since tension stress often governs the design of engineered wood-frame structural systems, the tension strength behaviour of framing material at elevated temperatures is critical to fire safety performance of such systems.

This paper reports the tensile strength behaviour of Machine Stress Rated (MSR) lumber exposed to temperatures up to $250^{\circ} \mathrm{C}$ under three different rates of loading, and the application of a damage accumulation model to predict the tension-strength behaviour at elevated temperatures. MSR lumber is used primarily for structural applications such as trusses and wood $I$ Beams.

\section{LITERATURE REVIEW}

Lumber strength is affected by many factors including temperature, grade, size, duration of load and moisture content. These factors are of concern in this paper. The immediate effect of temperature on the major mechanical properties of wood has been reviewed by Gerhards [2]. Most of these data were developed on small, clear specimens with moisture contents ranging from $6 \%$ to $20 \%$, and at temperature ranges between $-50^{\circ} \mathrm{C}$ and $100^{\circ} \mathrm{C}$. Generally, the effect of temperature on modulus of elasticity is linear and on strength properties is bi-linear to multilinear. Also, the effects are more prominent with increasing moisture content. Properties perpendicular-to-grain are affected to a greater extent than corresponding properties parallel-tograin. Compression strength is affected more severely than tension strength. Östman's study [3] showed that ultimate tension strength was more adversely affected than modulus of elasticity. For "full-size" specimens, Norén's work [4] on bending strength of 45-mm-thick spruce lumber exposed to fire indicated that strength reductions in partially pyrolysed wood can be as high as $75 \%$. The size effect on lumber strength has been traditionally approached from the standpoint of Weibull's weakest-link theory. Typically, the weakest link in the piece of lumber is associated with a defect - notably, a "large" knot. A longer piece of lumber is considered to be made up of a larger number of links, and, therefore, is more likely to process a weaker link. Generally, the weakest-link theory postulates a relationship in the form of:

$$
\frac{x_{1}}{x_{2}}=\left(\frac{y_{2}}{y_{1}}\right)^{\frac{1}{k}}
$$

where $x_{1}$ and $x_{2}$ are the respective strengths of members of dimension $y_{1}$ and $y_{2}$. The value of $k$ is found from experiment and it depends on whether the mode of stress is compression, tension or 
bending, and whether the dimension involved is length, depth, or breadth $[5,6,7]$. It also shows some strength and species dependencies. No data are available to indicate its dependency on temperature.

The duration-of-load (DOL) effect in wood refers to the behaviour of wood in response to longterm loadings; that is, its load-carrying capacity decreases as the length of time it is required to carry a load increases. Karacabeyli [8] observed that this effect in lumber does not depend on the quality or size of material. Gerhards [9], on the contrary, reported that lower-grade lumber tended to have shorter times to failure when tested at room temperature, but the effect had become less pronounced in shorter durations. From these studies, there exists little or no indication of a grade effect on the effect of load duration, for load durations of one hour or less at temperatures up to $55^{\circ} \mathrm{C}$. Foschi et al. [10] suggested that there was no DOL effect at room temperature if the stress was less than a certain proportion of the initial strength. On the other hand, at temperatures near the charring temperature of wood, significant DOL effect on creep had been observed in clear wood for time periods as short as two hours [11]. However, one problem with the data is that the effect of pyrolysis had not been isolated out.

It is well known that as wood absorbs water into its cell wall its strength is reduced. During fire exposure, moisture plays two additional roles: it modifies the apparent heat conduction characteristics of wood and it retards charring by taking up heat of vaporization [12]. Since the moisture content of a wood member changes when it is exposed to fire and since moisture content can not be reliably measured by any conventional means at temperatures near charring, it will be difficult to isolate the effect moisture on fire endurance during a fire exposure test.

TABLE 1. Experimental design and sample size of each different combination of variables of the experiment

\begin{tabular}{lcccc}
\hline Rate of loading & \multicolumn{4}{c}{ Temperature of exposure $\left({ }^{\circ} \mathrm{C}\right)$} \\
\cline { 2 - 5 }$(\mathrm{kN} / \mathrm{s})$
\end{tabular}

\section{EXPERIMENTAL DESIGN}

"Matched" samples of structural lumber were exposed to elevated temperatures. Part-way through the exposure, the specimens were subjected to a tension test at a constant rate of loading until failure. The ramp-load history produced mimics stress histories experienced by wood members exposed to fire because char formed reduces cross-sectional area. Table 1 shows the experimental variables and sample sizes for individual test groups. The loading rate of $1.85 \mathrm{kN} / \mathrm{s}$ produced, on average, a failure time of one minute at room temperature. The other load rates $(0.2$ and 0.067 $\mathrm{kN} / \mathrm{s}$ ) led to mean failure times of approximately 10 and 30 minutes, respectively, at room temperature. Figure 1 shows schematically a typical heating and loading sequence in the experiment. In this case the exposure temperature was $200^{\circ} \mathrm{C}$. The test materials were heated by 
conductive heat transfer - through the wide faces of the specimens - with a pair of electricallyheated aluminum platens, measured $2440 \mathrm{~mm}$ long by $100 \mathrm{~mm}$ wide by $50 \mathrm{~mm}$ thick. The length of specimen subjected to exposure was approximately $2440 \mathrm{~mm}$ (exposed region). The heating mechanism was housed within a lumber tension machine. The origin of time $(t=0)$ was set when contact was made between the platens and the specimen. The platen temperatures were maintained at the exposure temperature throughout the test. The loading was initiated at 1500 seconds $\left(t_{0}=1500 \mathrm{~s}\right)$. The centre-point temperature of the specimen at two points, $610 \mathrm{~mm}$ from the centre, was measured with ungrounded, type-K thermocouple probes sleeved with stainless steel. These probes had a outside diameter of $1.6 \mathrm{~mm}$. Holes of the same diameter were drilled to $17.5 \mathrm{~mm}$ deep from the narrow face of the specimens to accommodate the probes. The heating and loading histories were recorded. Values computed were the maximum tension load and the time to failure.

Assumptions. The analytical procedures TEMPERATURE $\left({ }^{\circ} \mathrm{C}\right)$
LOAD (kN) discussed assume that the sample groups have 300 the same distribution of the room-temperature tension strength, and that the location of the weakest point in the member does not depend 200 on temperature. Mean temperature is assumed to be a sufficient parameter for predicting temperature effects.

Material Sampling. Approximately 1200 pieces Machine-Stress-Rated (MSR), $2 \times 4$ Spruce-Pine-Fir (SPF) lumber were sampled. This species group constitutes a major source of softwood lumber in North America. The materials were taken from three MSR grades in equal quantities - to yield a wide strength

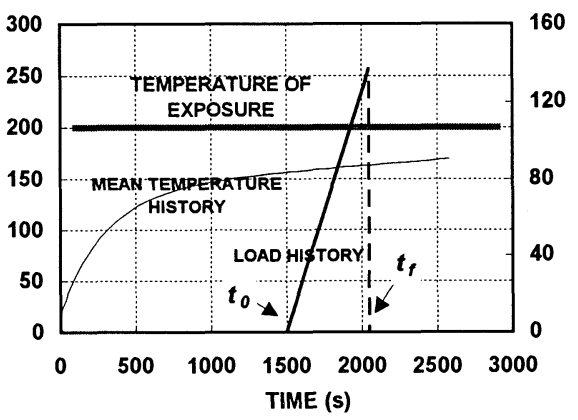

Figure 1. A typical heating and loading history of the tests range. The final moisture content of the specimens was approximately $9-11 \%$. The specimens were planed to a thickness of $35 \mathrm{~mm}$ from a nominal thickness of $38 \mathrm{~mm}$ so that the wide surfaces were uniform for heating. Finally, each specimen was evaluated for the modulus of elasticity (MOE) value using a MSR grading machine. Based on this ranking of the MOE value, groups of 60 specimens were formed in a systematic fashion.

\section{RESULTS AND DISCUSSION}

\section{Failure Characteristics}

As expected, most specimens failed in an abrupt manner consistent with a brittle material. Failures occurred mostly near a knot or knot cluster. There were no significant differences among the various groups as far as mode of failure was concerned or in the manner with which failure occurred. However, the higher the temperature, the lesser was the vigor of the failure. In most of the high-temperature tests, stains deposited by escaping vapour and volatile were easily spotted 
around the knots. Longitudinal and radial drying checks were abundant, especially near knots where stresses in tension perpendicular-to-grain would be quite high.

Failures outside Exposed Region. About 20\% of the specimens of the room-temperature test failed outside the exposed region as expected. These specimens had to be treated appropriately in order that the room-temperature results could serve as references for the high-temperature results. The "product limit" method of estimation was used to estimate the cumulative distribution of the tension strengths based on survival probabilities [13]. The outside failures were treated - not discarded - as "censored information" in the sense that we know that the strength of the exposed region was higher than the observed value. For a sample contributing censored information, we can write

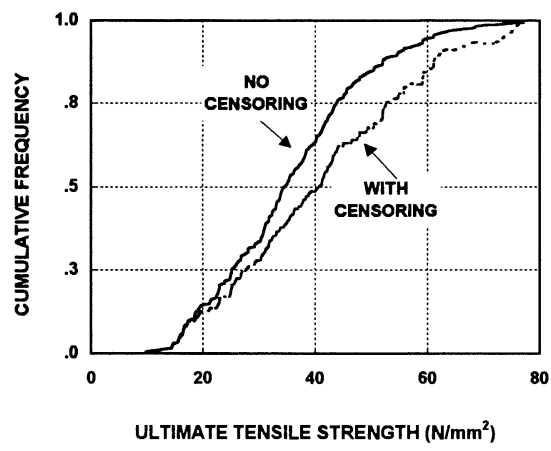

Figure 2. Cumulative frequency distributions of sample containing outside failures

$F\left(x^{\prime}\right)=1-\prod_{i=1}^{k}(n-i) /(n-i+1)$

where $F(x)$ is the non-parametric cumulative distribution of $x^{\prime}, k$ is defined by $x_{k} \leq x^{\prime} \leq x_{k+1}, n$ is the original sample size, $i$ is the order of a failed specimen in the complete sample including the "censored information". Note that Eqn 2 reduces to

$F\left(x^{\prime}\right)=i / n$

when there is no censored information in the sample. Eqn 3 is the nonparametric cumulative distribution function of typical uncensored samples. Figure 2 shows how the CDF of the roomtemperature groups tested at the loading rate of $1.85 \mathrm{kN} / \mathrm{s}$ is shifted by the censoring. This is intuitively correct since, on average, the failure strength of the centre $2440-\mathrm{mm}$ portion ought to be higher than that of the full-length $(4880 \mathrm{~mm})$ because of the size effect in wood.

\section{Temperature Distributions within Specimens}

The variations in temperature in response to any one temperature of exposure were affected by the initial moisture content of the specimens, and to a lesser extent, by the density of the specimens. Generally, specimens with higher initial moisture content tended to be lower in temperature because higher latent heat was required to evaporate the moisture. Higher exposure temperatures also led to higher variations. The coefficients of variation of the centre-point temperature of any individual sample at any given time of exposure ranged from 1 to $3 \%$. Temperature variations were insignificant in the lengthwise direction of the exposed region. Temperatures across the thickness of the specimens were parabolically distributed of which the mean $(T)$ was estimated by

$$
T=\left(2 T_{\mathrm{C}}+T_{\mathrm{S}}\right) / 3
$$


where $T_{\mathrm{C}}$ is the temperature at the centre and $T_{\mathrm{S}}$ is the temperature at the surfaces. Eqn 4 was used to calculate the mean temperature history of the specimens required for the $t_{\mathrm{f}}$ modelling. A typical mean temperature history for the temperature of exposure of $200^{\circ} \mathrm{C}$ is shown in Figure 1.

\section{Strength Distributions}

The room-temperature tension strength obtained with the rate of loading of $0.2 \mathrm{kN} / \mathrm{s}$ is, by definition, the characteristic short-term strength of wood. This property serves as the benchmark from which design values are derived. It will later be shown that the results from the other two rates of loading at room temperature are not significantly different, indicating that the rate of loading effect at these rates is eligible under room-temperature conditions.

Figures 3 (a), (b), and (c) show the cumulative frequency of the maximum tension strength, plotted by group, respectively for each of the three rates of loading. The absence of appreciable differences in the cumulative frequency distributions among those groups tested at room temperature suggests that the samples were indeed satisfactorily matched. Statistically, the null hypothesis that the data sets are consistent with a single distribution can not be rejected by the Kolmogorov-Smirnov (K-S) statistics.

Effect of Rate of Loading. The effect of rate of loading can also be observed in Figure 3. No significant differences at room-temperature can be found between the three rates of loading (compare the results among (a), (b) and (c) in Figure 3). Although this finding did not concur with Karacabeyli and Barrett's derived relationship [14], in which the mean strength should have declined by approximately $5 \%$ from the highest rate to the lowest rate, such a discrepancy is to be expected when the mean time to failure is relatively short, such as ours. It is without doubt that at the higher temperatures, the effect of rate of loading would be more pronounced than at room temperature. At the same time, slower rates of loading means longer exposure time, and therefore higher strength reduction due to pyrolytic effect. Since the two effects occurred simultaneously, a direct segregation of the two effects is not feasible.

As expected, the strengths of the high-temperature groups were significantly lower than the roomtemperature results (Figure 3 ). In the most severe case of exposure $\left(250^{\circ} \mathrm{C}\right)$, the mean reductions in strength ranged from 50 to $70 \%$ depending on the rate of loading.

\section{Modelling Mean Short-term Strength}

This section discusses the application of a damage-accumulation model developed in [16] to predict the short-term strength of SPF MSR lumber at elevated temperatures up to the charring temperature of wood for various durations up to $3600 \mathrm{~s}$. The analytical procedures discussed are generally applicable to any prescribed temperature histories below those for charring and any constant-load or ramp-load stress histories. Note that the effect has been examined on the basis of mean value using the initial strengths of our test material as inputs.

Model Description. In generalizing the approach based on damage accumulation [15], we may write 
(a) $1.85 \mathrm{kN} / \mathrm{s}$

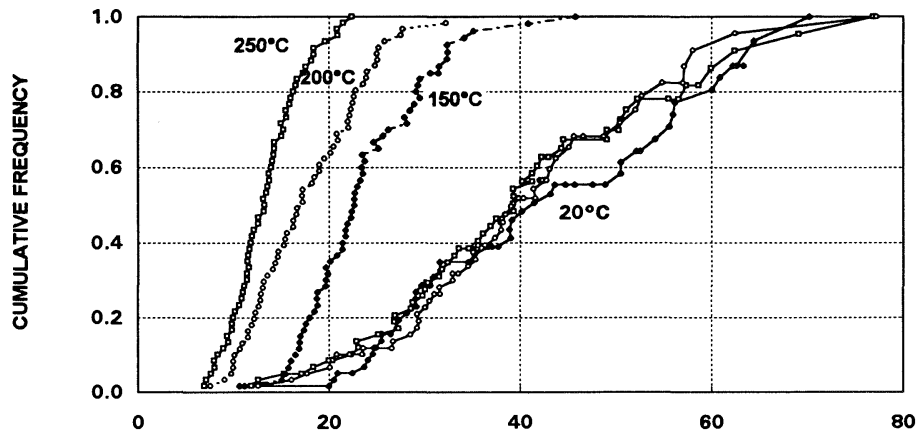

(b) $0.2 \mathrm{kN} / \mathrm{s}$

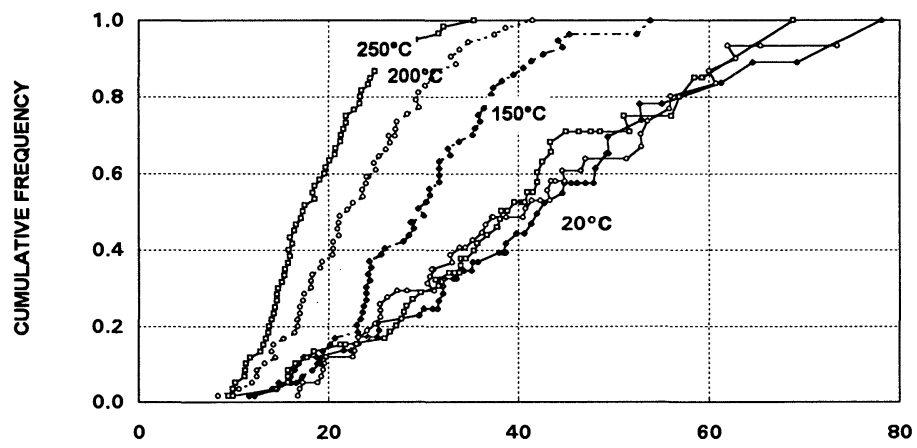

(c) $0.067 \mathrm{kN} / \mathrm{s}$

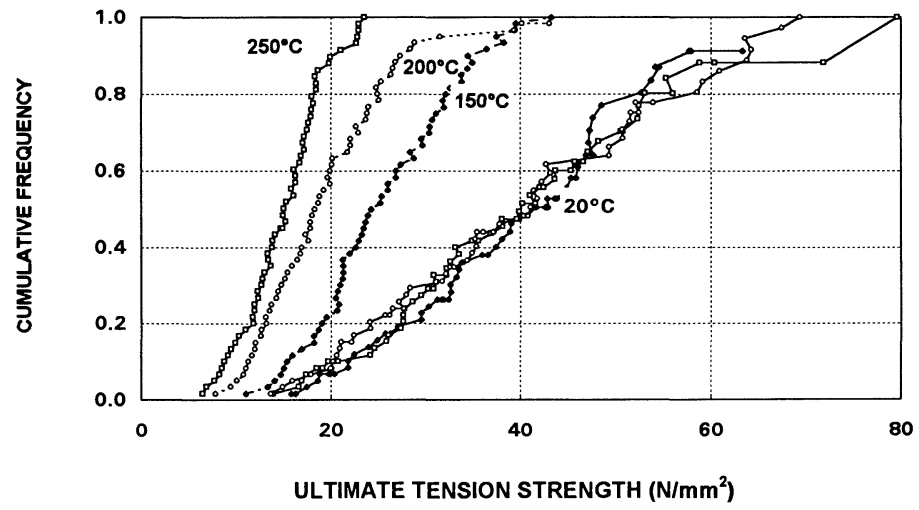

Figure 3. The cumulative distributions of the ultimate tension strength plotted by temperature of exposure and rate of loading 
$\frac{\partial \alpha}{\partial t}=F(\tau(t), T(t), \alpha)$

where the rate of damage, $\partial \alpha / \partial t$, in a unit volume of material at any time $t$ is expressed as a function of the stress $\tau(t)$, the temperature $T(t)$ at the time, and the damage $\alpha$ accumulated to the time. Failure is assumed to occur when $\alpha=1$. The damage accumulation model developed by Lau [16] was derived from a kinetic theory for strength-loss as a function of temperature and stress histories [15], coupled with a Arrhenius term, to express the pyrolytic process as a form of damage. The model has four independent parameters $-a_{1}, a_{2}, a_{3}, a_{4}-$ and requires the shortterm strength of the lumber as an input. The parameters have the implied meaning of: $a_{1}=E / R$, $a_{2}=\psi, a_{3}=\omega_{\mathrm{bb}}$ and $a_{4}=\beta$, where $E$ is the activation energy for breaking and reforming of bonds in wood, $R$ is the universal gas constant, $\omega_{\mathrm{b}}$ is the frequency of jump motion of "elements" in wood with respect to the bond breaking process, $\psi$ is the pre-exponential constant in an Arrenhius equation for weight loss, and $\beta$ is a positive quantity that modifies the activation energy as a consequence of an applied stress in the kinetic strength model. Specifically,

$$
\frac{d \alpha}{d t}=\exp \left(-\frac{a_{1}}{T(t)}\right)\left[a_{2}+(1-\alpha) a_{3} \exp \left(a_{4} \frac{\tau(t)}{(1-\alpha)}\right)\right]
$$

The initial value of $\alpha$ is given by

$$
\left.\alpha\right|_{t=0}=1-\frac{\sigma_{0}}{\sigma^{*}}
$$

where $\sigma^{*}$ is a parameter depending on $a_{1}, a_{4}$ and the initial short-term strength $\sigma_{0}$. The failure is governed by the criterion

$$
\left.\alpha\right|_{t=t_{\mathrm{f}}}=1
$$

The model parameters for our tension strength data were: $a_{1}=16400 \mathrm{~K} ; a_{2}=10^{10} \mathrm{~s}^{-1} ; a_{3}=$ $1.8 \times 10^{7} ;$ and $a_{4}=0.065 \mathrm{~mm}^{2} \mathrm{~N}^{-1}$. These values compare favorably with similar values published in literature. The dependent variable $\sigma^{*}$, after having substituted the values for $a_{1}$ and $a_{4}$, was given by

$$
\sigma^{*}=\exp \left(\frac{0.463}{\sigma_{0}}\right)\left(-0.218 \sigma_{0}+508.0\right)
$$

Model Predictions. The short-term strength of the test material at a temperature $T$ and for a duration $t$ was determined by entering into the model a hypothetical stress history equivalent to a strength test

$$
\begin{array}{ll}
\tau(t)=\frac{k_{0}}{A}\left(t-t_{0}\right) & \text { for } t>t_{0} \\
\tau(t)=0 & \text { for } t \leq t_{0}
\end{array}
$$

where $\tau(t)$ was the stress, $A$ was the cross-section area of the member, $k_{0}$ was the rate of loading corresponding to the definition of short-term strength of lumber, and $t_{0}$ was the time at which the hypothetical stress history begins (see Figure 1). To minimize any duration-of-load effect, particularly at elevated temperatures, $k_{0}=1.85 \mathrm{~N} / \mathrm{s}$ was used. The input temperature history was 
$T(t)=C$ where $C$ was any constant temperature. The resulting value $\tau\left(t_{f}\right)$ was the short-term strength of the material at the $t_{\mathrm{f}}$ determined by the model. The value was expressed as a ratio to the short-term strength at room temperature obtained using the rate of $0.2 \mathrm{kN} / \mathrm{s}$ (strength ratio).

In the analysis, a sample of $500 \sigma_{0}$ was generated from the nonparametric distribution of the room-temperature short-term strength. For a given start time $t_{0}$ and for each $C$ with the generated sample values of $\sigma_{0}$, a total of $500 t_{\mathrm{f}}$ values were predicted using the model. The mean $t_{\mathrm{f}}$ was calculated. The stress $\tau=k_{0} \cdot\left(\right.$ mean $\left.t_{\mathrm{f}}\right)$, where $k_{0}=1.85 \mathrm{kN} / \mathrm{s}$, gave the mean short-term strength at the temperature $C$ and for the duration mean $t_{\mathrm{f}}$. The above process was repeated for various $t_{0}$ values ranging from $5 \mathrm{~s}$ to $3600 \mathrm{~s}$.

Calculated mean short-term strengths, for durations $\left(t_{\mathrm{f}}\right)$ of $120,600,1800$, and $3600 \mathrm{~s}$, are plotted in Figure 4 against input temperature $C$. The strength-ratios as obtained are, approximately, 0.9 at $50^{\circ} \mathrm{C}, 0.7$ at $100^{\circ} \mathrm{C}, 0.4$ at $200^{\circ} \mathrm{C}$, and 0 at $290^{\circ} \mathrm{C}$. Generally, for temperatures up to $150^{\circ} \mathrm{C}$, the relationships are approximately linear and not significantly different among the different durations evaluated. From $150^{\circ} \mathrm{C}$ upward, the effect of temperature increases sharply, and duration starts to become important. At these higher temperatures, longer durations tend to reduce the temperature needed to effect the same reduction in strength. For example, it takes 120 $\mathrm{s}$ to reduce the material to zero strength at $290^{\circ} \mathrm{C}$, compared to $3600 \mathrm{~s}$ at only $200^{\circ} \mathrm{C}$. The predictions given in Figure 4 provide the temperature-duration-strength relationship required for structural analyses of light-frame members exposed to elevated temperatures.

Shown also in Figure 4 are tension strength data of Östman [7], Knudson and Schniewind [18], and Schaffer [11] on small, dry and clear specimens of spruce or Douglas-fir. The comparisons

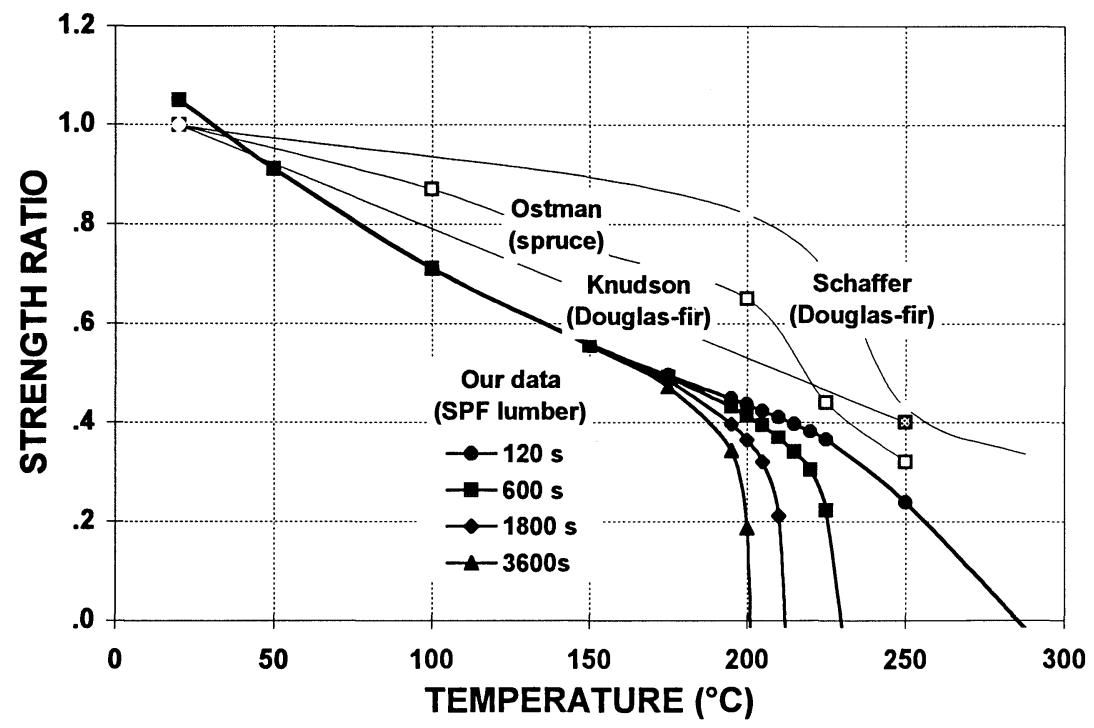

Figure 4. Effect of temperature on the short-term strength as predicted using the damage accumulation model 
with these data show that lumber at $9-11 \%$ moisture content is more adversely affected by temperature than small, dry and clear specimens - which is not surprising since lumber strength is determined by defects and they are affected more severely than clear-wood material. One observation, common to every set of data shown, is the sharp increase in the temperature effect at approximately $200^{\circ} \mathrm{C}$. This phenomenon is probably caused by a change in the failure mechanism, a change in the heat conduction characteristics of the material, or perhaps a phaseshift of the cellulose fraction to glassy state.

\section{CONCLUSIONS AND RECOMMENDATIONS}

The failure mode of lumber subject to tension and temperatures up to $250^{\circ} \mathrm{C}$ is generally brittle in nature. Short-term strength is significantly reduced by temperatures above $150^{\circ} \mathrm{C}$. Also, longer durations of exposure lead to higher reductions in strength at temperatures above $150^{\circ} \mathrm{C}$. The rate-of-loading effect is insignificant at room temperature for the range of rates evaluated.

The model developed in Lau [16] predicts that temperature effects on strength of lumber in tension are approximately linear for temperatures up to $150^{\circ} \mathrm{C}$. Also, at or below this temperature, durations up to one hour is not important. Both temperature and duration effects increase sharply as temperature is increased above $150^{\circ} \mathrm{C}$. Generally, lumber at $9-11 \%$ moisture content is more adversely affected by temperature than small, dry and clear specimens.

The results of this study should be complemented with tests based on transient temperature conditions. One such test should involve a constant load applied at all times from ambient conditions onward until failure.

The tension strength behaviour at subcharring temperatures will be an important factor in fire endurance designs involving light-frame members. The study should be extended to compression strength which is as susceptible or more to elevated temperature effects as tension strength. In rehabilitating a fire-exposed structure, the residual strength and stiffness of wood members exposed to fire should be critically examined. Since strength-loss in partially pyrolysed wood is quite substantial, for those members showing signs of charring, a significant change in the colour of the wood to a brownish colour, longitudinal drying checks, or a significant showing of staining around knots, the residual strength is unlikely to recover significantly after the members return to normal end-use conditions and they should be replaced. On the other hand, for those members suffering some exposure but without those significant signs of degradation, they may be rehabilitated. Work should be done to clarify the extent of recovery for various grades of lumber.

Closing Remarks. In designing a structural wood member for fire safety, we seek to ensure, with high confidence, that the member will survive a "severe" fire for a specified period. Reliability analysis allows one to express this confidence in terms of a probability of survival. This probability not only allows the safety of a structure to be analyzed in relative terms, but also permits a costbenefit analysis to be carried out comparing alternative design solutions at the same overall safety level. It is a preferred approach of modern design processes. The current movement is toward a performance-based code format, with performance and performance expectations stated in terms of risk to human life and fire cost. Within such an approach, current methods of determining fire 
resistance rating no longer provide relevant information. These methods must be revised to produce more accurate performance information. The ultimate objective must be to determine the fire endurance of wood structural members during real fire exposures, and to express the endurance in terms of a time to failure model.

\section{Acknowledgment}

Forintek Canada Corp. would like to thank its industry members, Natural Resources Canada (Canadian Forest Service), and the Provinces of British Columbia, Alberta, Ontario, Quebec, Nova Scotia and New Brunswick, for their guidance and financial support for this research.

\section{LITERATURE CITED}

1. Brannigan, F. L., Building Construction for the Fire Service, 3rd Ed. National Fire Protection Association. Batterymarch Park, Quincy, Massachusetts, 1992.

2. Gerhards C. C., "Effect of moisture content and temperature on the mechanical properties of wood: an analysis of immediate effects", Wood and fiber, 14(1), 4-36, 1982.

3. Östman, B. A-L., "Wood Tensile Strength at Temperatures and Moisture Contents Simulating Fire Conditions", Wood Science and Technology, 19, 103-116, 1985.

4. Norén, J. B., "Failure of Structural Timber when Exposed to Fire", In Proc. 1988 International Conference on Timber Engineering, ed. by R. Y. Itani, Washington State University, WA, pp. 397-406, September 1988.

5. Buchannan, B., Effect of Size on Bending Strength of Wood Members, USDA, Forest Service, Research Paper FPL 56, Forest Products Laboratory, Madison, WI., 1966.

6. Madsen, B. and Buchanan, A. H., "Size Effects in Timber Explained by a Modified Weakest Link Theory", Can. J. Civ. Eng., 13:218-232, 1986.

7. Madsen, B. and Stinson, T., In-grade Testing of Timber Four Inches or more in Thickness, Structural Research Series, Dept. of Civil Engineering, University of British Columbia, 1982.

8. Karacabeyli, E., "Duration of Load Research for Lumber in North America", in Proc. 1988 International Conference on Timber Engineering, ed. by R. Y. Itani, Washington State University, Seattle, WA, pp. 380-389, September 1988.

9. Gerhards, C.C., "Time-Related Effects on Wood Strength: A Linear-Cumulative Damage Theory", Wood Science, 11(3):138-144, 1979. 
10. Foschi, R. O., Folz, B. R. and Yao, F. Z., Reliability-Based Design of Wood Structures. Structural Research Series, Report No.34, Dept. of Civil Engineering, University of British Columbia, Vancouver, Canada, 1989.

11. Schaffer, E. L., "Effect of Pyrolytic Temperature on the Longitudinal Strength of Dry Douglas-Fir", J. of Testing and Evaluation, 1(4):319-329, 1973.

12. White, R. and Schaffer, E., "Transient Moisture Content in Fire-Exposed Wood Slab", Wood and Fiber, 13(1):17-38, 1981.

13. Bury K. V., Statistical Models in Applied Science. John Wiley \& Sons, New York, 1975.

14. Karacabeyli, E. and Barrett J. D., "Rate of Loading Effects on Strength of Lumber", Forest Prod. J. 43(5):28-36, 1993.

15. Miner, M. A. "Cumulative Damage in Fatigue", J. of Applied Mechanics 67, A159-A164, 1945.

16. Lau, P. W., Behaviour and Reliability of Wood Structural Elements Exposed to Elevated Temperatures, Ph.D. Thesis, University of British Columbia, Vancouver, Canada.

17. Hsiao, C. C. Moghe, S. R. and Kausch von Schmeling, H. H., "Time-Dependent Mechanical Strength of Oriented Media", J. Applied Physics, 39(8):3857-3861, 1968.

18. Knudson, R. M. and Schniewind, A. P., "Performance of Structural Wood Members Exposed to Fire", Forest Products J., 25(2):23-32. 